\title{
Modified Microstrip Aperture Coupled Patch Antenna with Sierpinski Fractal Geometry
}

\author{
Hao Jiang, Weiming Li, and Zhenghui Xue \\ School of Information and Electronics, Beijing Institute of Technology, Beijing 100081, China \\ Correspondence should be addressed to Zhenghui Xue; zhxue@bit.edu.cn
}

Received 23 October 2013; Accepted 31 December 2013; Published 19 February 2014

Academic Editor: Zhaobiao Lv

Copyright (C) 2014 Hao Jiang et al. This is an open access article distributed under the Creative Commons Attribution License, which permits unrestricted use, distribution, and reproduction in any medium, provided the original work is properly cited.

\begin{abstract}
A two-layer modified microstrip aperture coupled patch antenna with Sierpinski fractal geometry is presented in this paper. The effects of the two coupling slots and the parasitic patch are discussed. The proposed antenna can work on $956 \mathrm{MHz}$ to $968 \mathrm{MHz}$, $3.654 \mathrm{GHz}$ to $3.78 \mathrm{GHz}$, and $8.81 \mathrm{GHz}$ to $9.28 \mathrm{GHz}$ three frequency bands, and the maximum gain in each band is $4.64 \mathrm{dBi}, 8.46 \mathrm{dBi}$, and $7.85 \mathrm{dBi}$, respectively. The simulated result reveals that the Sierpinski patch antenna we proposed in this paper performs better on radiation properties.
\end{abstract}

\section{Introduction}

Fractal geometry has been proved as an alternative design methodology to design miniature antennas like miniature microstrip antennas using the Sierpinski bowtie [1] and Sierpinski gasket [2]. On the other hand, the self-similarity property of fractal shapes can fulfill the renewed interest in multiband antennas. A planar Sierpinski fractal antenna for multiband applications is proposed in [3]. Also, fractal geometry can be used to design high directivity patches [4]. As microstrip antenna is widely used in application, the authors $[5,6]$ widely investigate the combination of microstrip antennas together with fractal geometry, which give us the overview of the development of the fractal antenna.

There are many configurations used to feed microstrip antennas. Among them, microstrip feed line, coaxial probe, and aperture coupled feed are the popular ones. A stacked Koch island fractal antenna fed through a narrow $\mathrm{H}$-shaped aperture is introduced in [7] the bandwidth of the antenna can be $32 \%$ at the resonance frequency of $980 \mathrm{MHz}$, but the radiation pattern in the second or third frequency band is not discussed. And in [8], a self-affine fractal multiband antenna with aperture coupled feed is introduced. And three usable frequency bands at $2.44,4.88$, and $10.05 \mathrm{GHz}$ are obtained. However, the pattern at the third band exhibits considerable amount of ripple. This is due to the nonscalability of the ground plane. Moreover, with the increase of the frequency, the current distribution on the radiating patch becomes nonuniform, which usually leads to the low performance of the radiation behavior. A large number of works are concerned with compensating the influence caused by the nonuniformly distributed surface current. A two-layer stacked Sierpinski patch antenna is introduced in [9], where a top grid layer is used to provide stronger electromagnetic coupling between triangular patches. Unfortunately, the radiation property does not perform better at the third frequency band. And in [10], modifications on the Sierpinski gasket patch antenna made by shoring pins and discontinuities is proposed, in order to enhance the overall behavior in matching and radiation aspects. But the structure of the antenna is complicated and hard to fabricate.

In this paper, we present a two-layer Sierpinski carpet patch antenna fed by the modified aperture coupling, in order to achieve improved performance of impedance matching and radiation properties. The format of this paper is as follows. In Section 2, a Sierpinski carpet patch antenna fed by one coupling slot is discussed. By optimizing the location and the size of the coupling slot, we find that one coupling slot cannot satisfy the requirements of impedance matching and radiation aspects simultaneously. In Section 3, a twoslot coupling Sierpinski carpet patch antenna is introduced. 


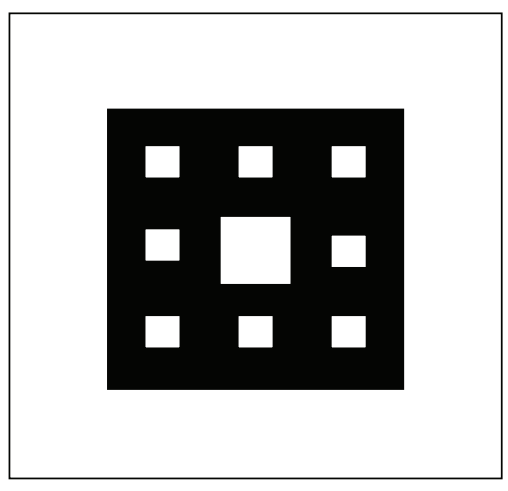

(a) Top view of the radiating layer

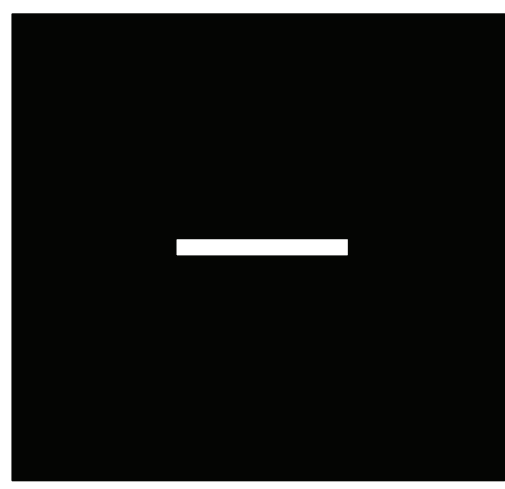

(b) Top view of the ground layer

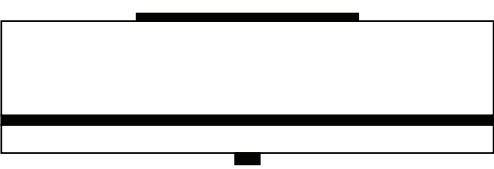

(d) The side view

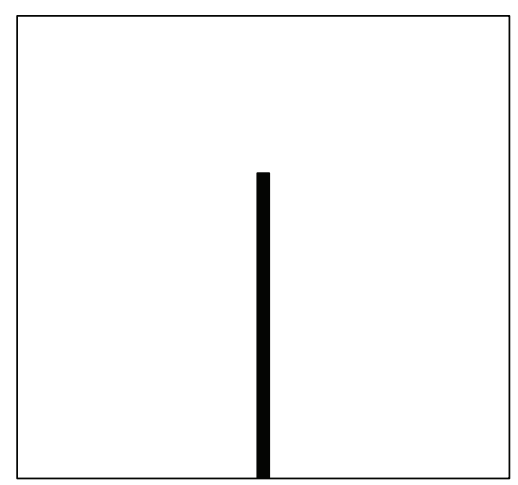

(c) Top view of the feed layer

FIGURE 1: Geometry of the aperture coupled Sierpinski patch antenna. (a) Top view of the radiating layer. (b) Top view of the ground layer. (c) Top view of the feed layer. (d) The side view.

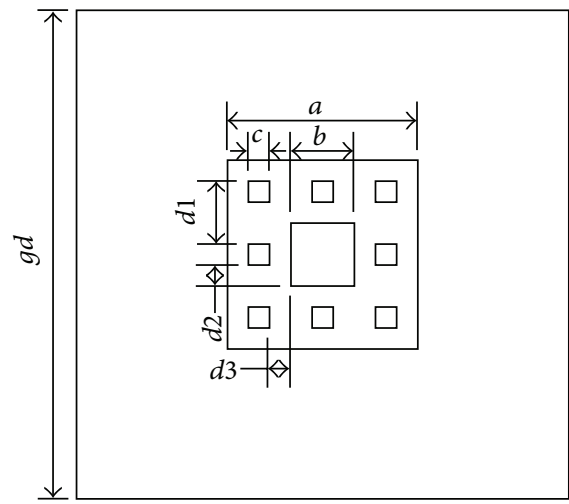

(a) Top view of the radiating layer

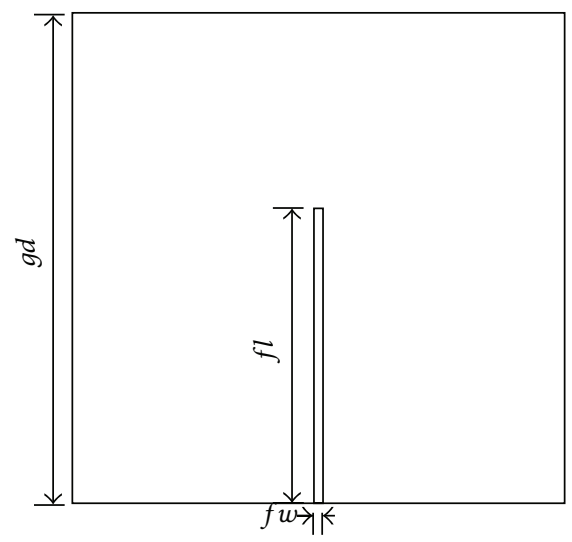

(c) Top view of the feed layer

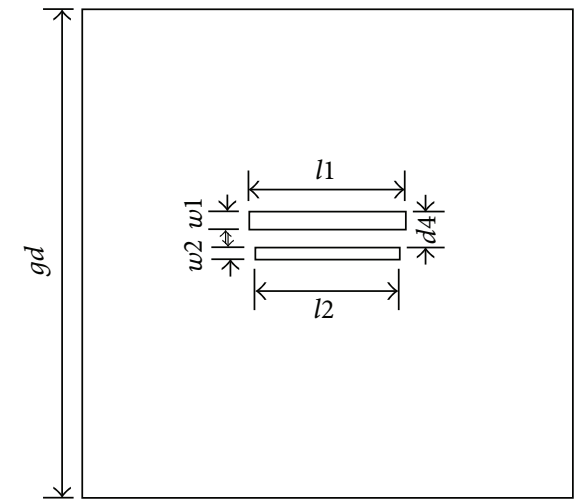

(b) Top view of the ground layer

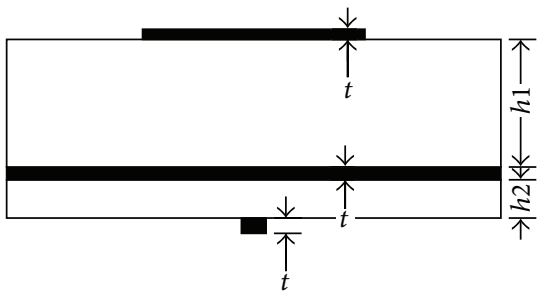

(d) The side view

FIGURE 2: Geometry of the modified aperture coupled Sierpinski patch antenna. (a) Top view of the radiating layer. (b) Top view of the ground layer. (c) Top view of the feed layer. (d) The side view. 


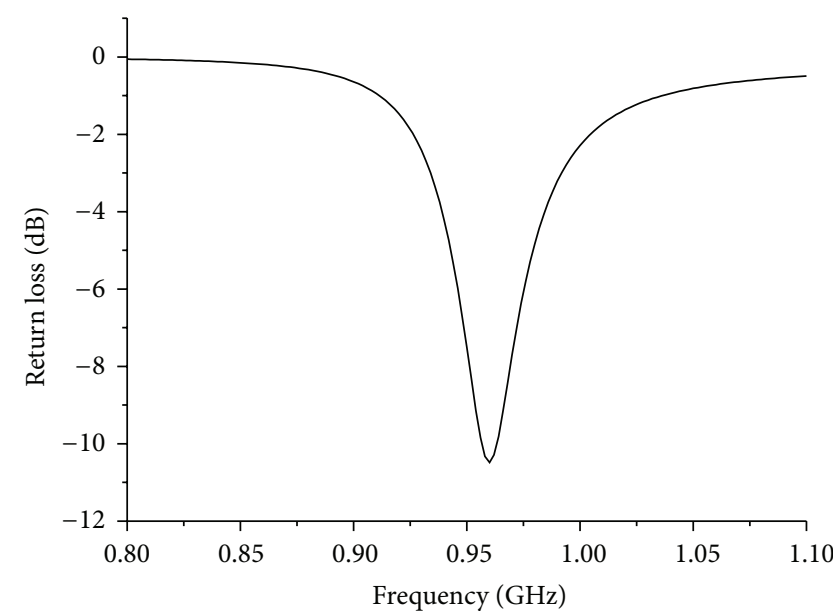

(a) The return loss from $0.8 \mathrm{GHz}$ to $1.1 \mathrm{GHz}$

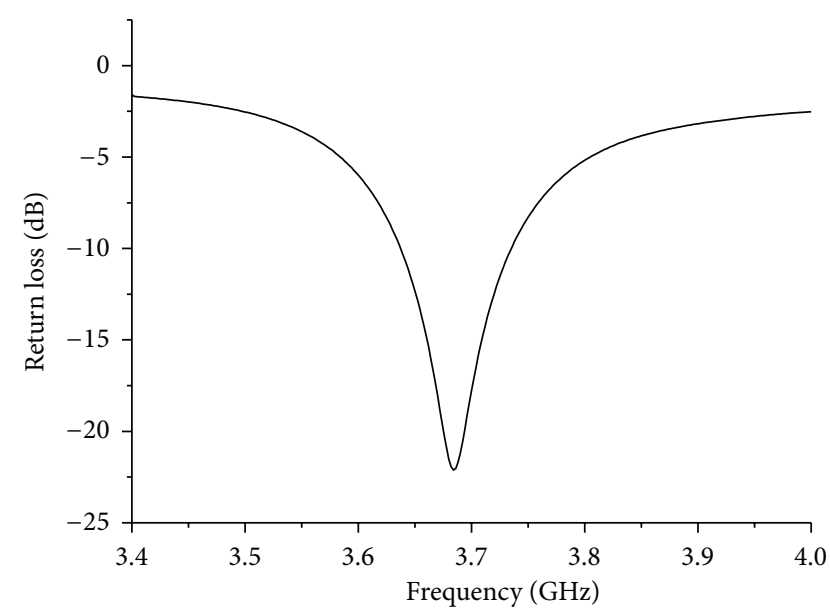

(b) The return loss from $3.4 \mathrm{GHz}$ to $4 \mathrm{GHz}$

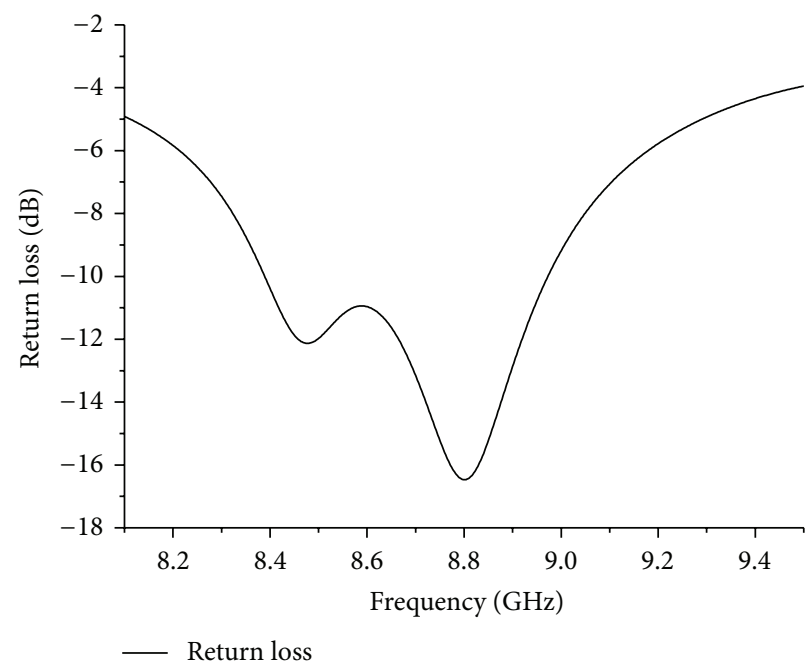

(c) The return loss from $8.1 \mathrm{GHz}$ to $9.5 \mathrm{GHz}$

Figure 3: The return loss of the proposed antenna. (a) The return loss from $0.9 \mathrm{GHz}$ to $1.1 \mathrm{GHz}$. (b) The return loss from $3.5 \mathrm{GHz}$ to $3.9 \mathrm{GHz}$. (c) The return loss from $8 \mathrm{GHz}$ to $9.1 \mathrm{GHz}$.

The effect of the two coupling slots is discussed, and the simulated results illustrate that the proposed antenna performs better on radiation behavior. In Section 4, modifications have been done on the antenna discussed in Section 3, that is, to add one parasitic layer upon the radiating patch to get a better directivity of the antenna. Section 5 is the conclusion.

\section{Characteristics of Sierpinski Patch Antenna with One Coupling Slot}

According to the theory of microstrip antenna, the structure of the antenna can be determined in [11], where $L$ and $w$, respectively, represent the length and width of the radiating patch, and $h$ represents the height of the substrate. The relative dielectric constant is $\varepsilon_{r}$. And $\varepsilon_{e}$ is the effective dielectric constant introduced to account for fringing and the wave propagation in the line. $\Delta l$ stands for the extended length on each side of the patch. Consider

$$
\begin{gathered}
w=\frac{c}{2 f_{r}}\left(\frac{\varepsilon_{r}+1}{2}\right)^{-1 / 2}, \\
\varepsilon_{e}=\frac{1}{2}\left[\left(\varepsilon_{r}+1\right)+\left(\varepsilon_{r}-1\right)\left(1+\frac{10 h}{w}\right)^{-1 / 2}\right], \\
\Delta l=0.412 h \frac{\varepsilon_{e}+0.3}{\varepsilon_{e}-0.258} \cdot \frac{w / h+0.264}{w / h+0.8} \\
L=\frac{c}{2 f_{r} \sqrt{\varepsilon_{e}}}-2 \Delta l .
\end{gathered}
$$




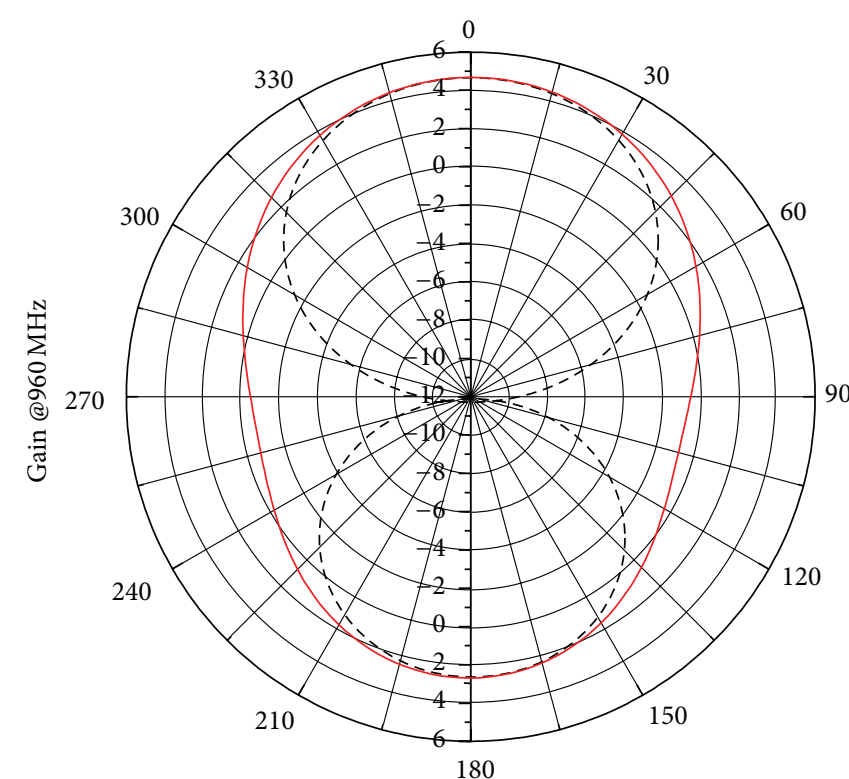

(a) The radiation pattern at $960 \mathrm{MHz}$

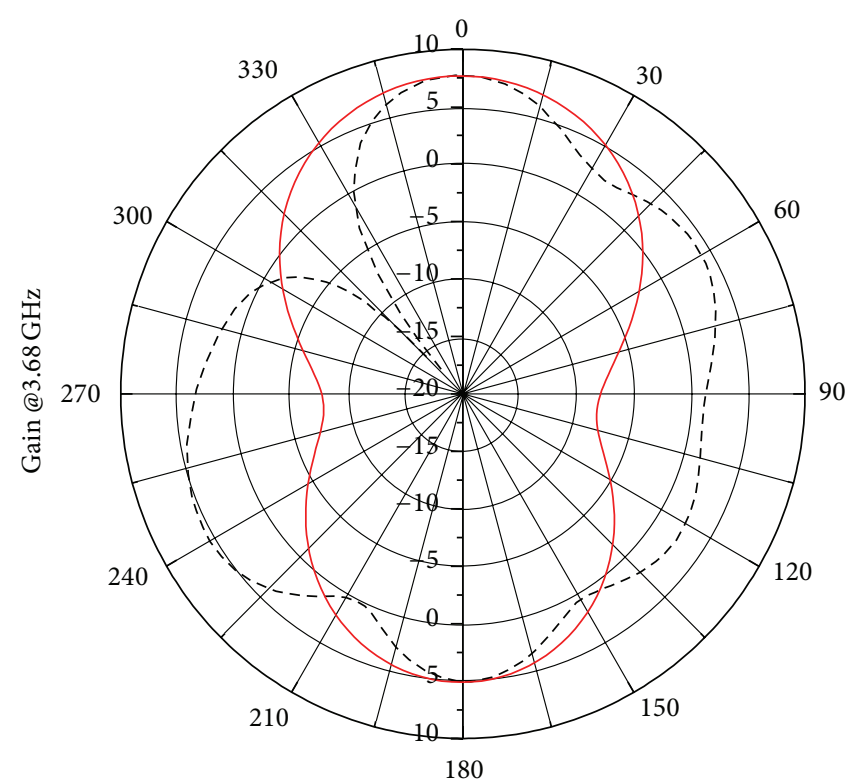

(b) The radiation pattern at $3.68 \mathrm{GHz}$

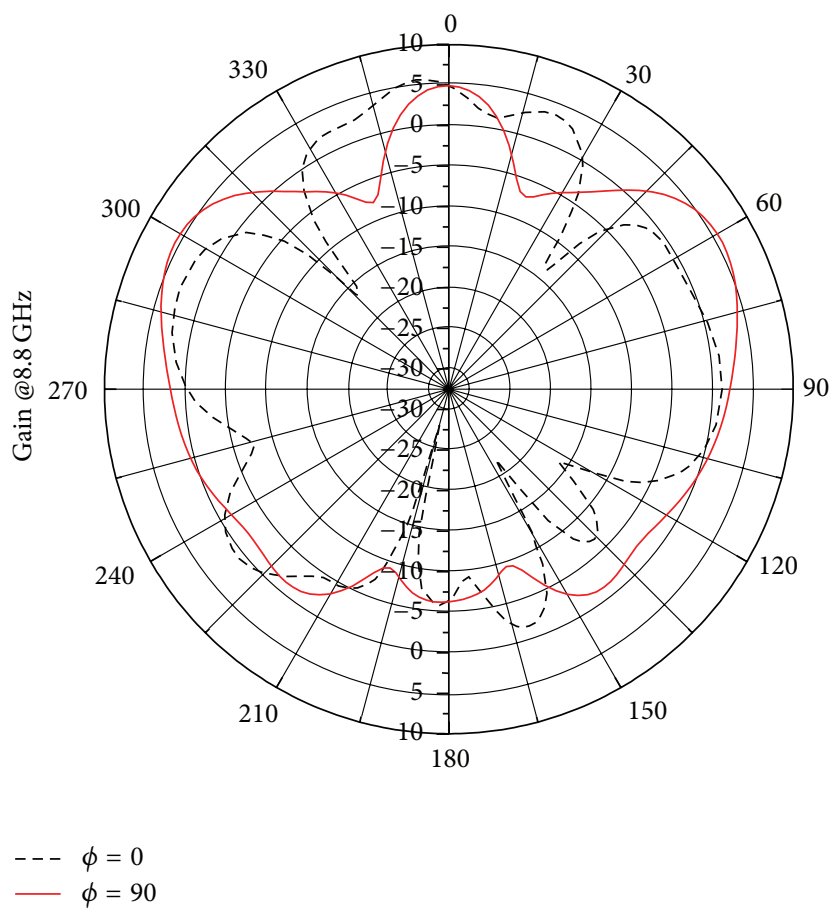

(c) The radiation pattern at $8.8 \mathrm{GHz}$

FIGURE 4: The radiation patterns of the proposed antenna. (a) The radiation pattern at $960 \mathrm{MHz}$. (b) The radiation pattern at $3.68 \mathrm{GHz}$. (c) The radiation pattern at $8.8 \mathrm{GHz}$.

The iterative process of the Sierpinski carpet antenna is based on the following rules [12]:

$$
\begin{gathered}
N_{n}=8^{n}, \\
L_{n}=\left(\frac{1}{3}\right)^{n}, \\
A_{n}=\left(\frac{8}{9}\right)^{n},
\end{gathered}
$$

where $N_{n}$ is the number of rectangles covering the radiating material, $L_{n}$ is the length ratio, and $A_{n}$ is the ratio for the fractional area.

In this paper, we choose aperture coupling to feed the antenna to get a better performance on the impedance matching. Firstly, one coupling slot is introduced to excite the patch antenna. The geometry of the proposed antenna is shown in Figure 1. The simulated result shows the antenna can work on three frequency bands near $1 \mathrm{GHz}, 3 \mathrm{GHz}$, and 


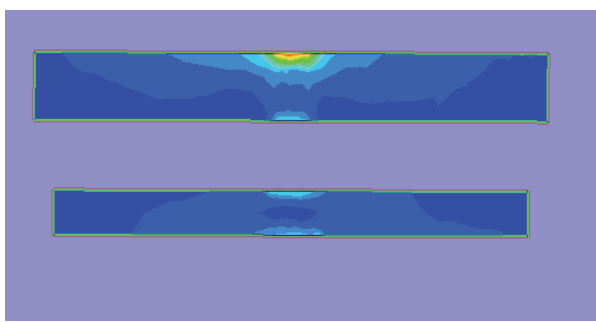

(a) The electric field near the coupling slots at $960 \mathrm{MHz}$

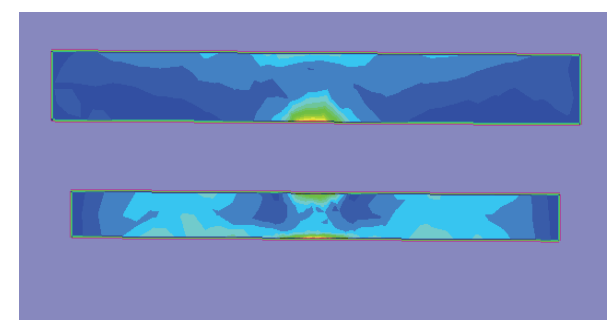

(b) The electric field near the coupling slots at $3.68 \mathrm{GHz}$

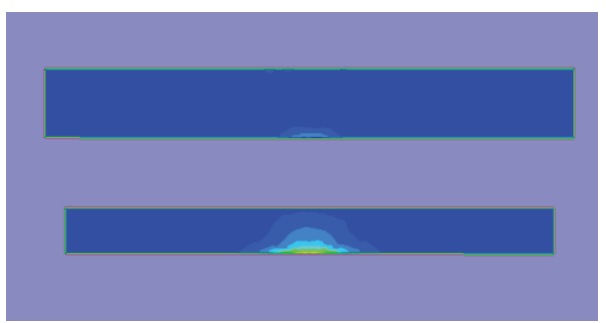

(c) The electric field near the coupling slots at $8.8 \mathrm{GHz}$

Figure 5: The magnitude of the electric field near the two slots. (a) The electric field near the coupling slots at $0.98 \mathrm{GHz}$. (b) The electric field near the coupling slots at $3.64 \mathrm{GHz}$. (c) The electric field near the coupling slots at $8.38 \mathrm{GHz}$.

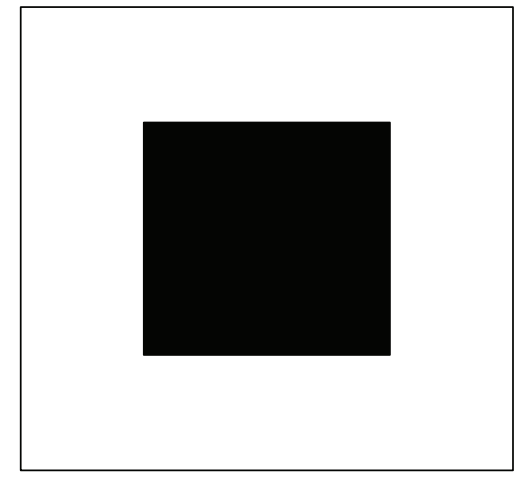

(a) The top view of the parasitic patch

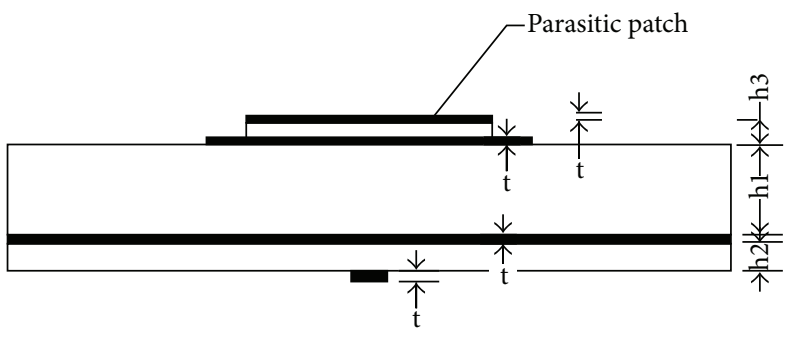

(b) The side view

FIgURE 6: Geometry of the two-layer Sierpinski patch antenna. (a) Top view of the parasitic patch. (b) The side view.

$9 \mathrm{GHz}$, respectively. By optimizing the location and the size of coupling slot, we find that when the coupling slot is located in the middle of the ground plane, the antenna can reach good radiation properties at the high frequency band, while it is hard to get a good impedance matching at the low frequency band. On the other hand, when the coupling slot is moved a little distance from the middle of the ground plane, the main lobe of the radiation pattern will not point to the normal direction of the antenna at the high frequency band. Thus, some modifications should be made on the coupling slot, so that the antenna can perform better both on the radiation properties and the impedance matching properties.

\section{Modified Aperture Coupled Sierpinski Patch Antenna}

As discussed in Section 2, in order to improve both the radiation properties at the high frequency band and have a good impedance matching at the low frequency band, some modifications can be made on the feed structure. In this Section, two coupling slots are introduced on the ground plane of the fractal antenna, one is large and another one is relatively small, as shown in Figure 2. The small one is located in the middle of the ground plane, in order to enhance the radiation properties, while the large one is located at a little distance from the small one to improve the impedance matching of the antenna. Thus, the two slots work together and make the modified antenna perform better than the ordinary one.

All the parameters used in the figure are to describe the structure of the elements which compose the antenna. In order to have a clear look of the structure of the antenna, the radiating patch, the ground, and the feed line are not filled with black. Table 1 shows the values of all the parameters used in Figure 2. The relative permittivity of the first and the second dielectric layers is 2.7 and 2.25 , respectively. 


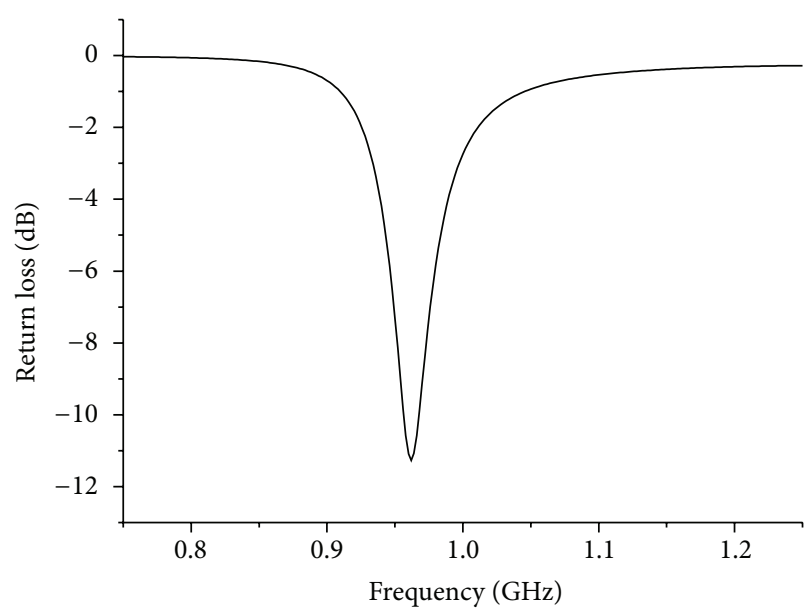

(a) The return loss from $0.75 \mathrm{GHz}$ to $1.25 \mathrm{GHz}$

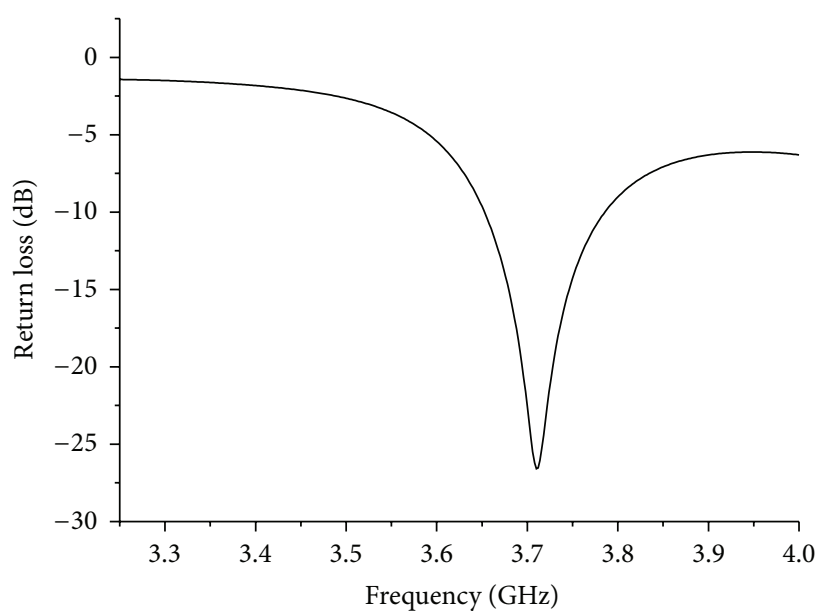

(b) The return loss from $3.25 \mathrm{GHz}$ to $4 \mathrm{GHz}$

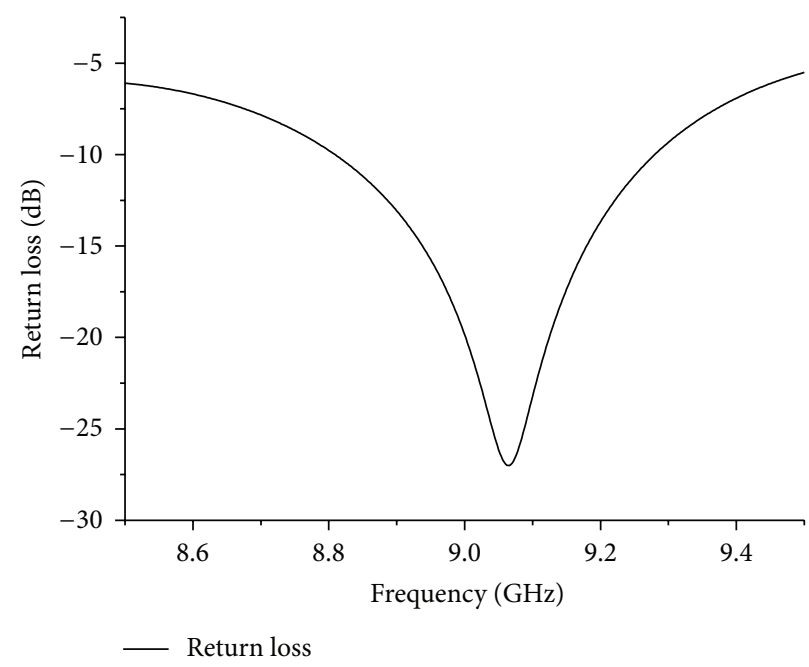

(c) The return loss from $8.5 \mathrm{GHz}$ to $9.5 \mathrm{GHz}$

Figure 7: The return loss of the two-layer Sierpinski patch antenna. (a) The return loss from $0.75 \mathrm{GHz}$ to $1.25 \mathrm{GHz}$. (b) The return loss from $3.25 \mathrm{GHz}$ to $4 \mathrm{GHz}$. (c) The return loss from $8.5 \mathrm{GHz}$ to $9.5 \mathrm{GHz}$.

The simulated result of the return loss and radiation pattern of the antenna are shown in Figures 3 and 4. It clearly shows in Figure 3 that this antenna can work on $956 \mathrm{MHz}$ to $964 \mathrm{MHz}, 3.64 \mathrm{GHz}$ to $3.73 \mathrm{GHz}$, and $8.39 \mathrm{GHz}$ to $8.97 \mathrm{GHz}$ three frequency bands. The simulated results of radiation pattern at $960 \mathrm{MHz}, 3.68 \mathrm{GHz}$, and $8.8 \mathrm{GHz}$ perform well. And the gain of the antenna at each frequency is $4.56 \mathrm{dBi}$, $7.87 \mathrm{dBi}$, and $4.82 \mathrm{dBi}$. At $8.3 \mathrm{GHz}$, the main lobe of the radiation pattern still point to the normal direction of the antenna. Compared with the radiation pattern of the ordinary antenna in the third band, of which the main lobe is divided into two parts, it is clear that the two coupling slots have a great effect on the excitation and radiation properties.

In order to see how the two coupling slots work, we choose to observe the electric field near the two slots. The magnitude of the electric field is shown in Figure 5. When the antenna works on the first frequency band, it will be excited mainly by the large slot. When the antenna works on the second frequency band, it will be excited by two slots. And
TABLE 1: The values of all the parameters used in Figure $1(\mathrm{~mm})$.

\begin{tabular}{lccccc}
\hline$a$ & $b$ & $c$ & $d 1$ & $d 2$ & $d 3$ \\
\hline 63 & 21 & 7 & 21 & 7 & 7 \\
\hline$l 1$ & $w 1$ & $l 2$ & $w 2$ & $f w$ & $f l$ \\
\hline 52 & 6 & 44 & 4 & 3 & 58 \\
\hline$d 4$ & $g d$ & $t$ & $h 1$ & $h 2$ & \\
\hline 12 & 83 & 0.2 & 6 & 1 & \\
\hline
\end{tabular}

when the antenna works on the third frequency band, it will be excited mainly by the small slot. Different frequency bands are excited by different combinations of slots. And it is clearly revealed that the first frequency band is mainly influenced by the small coupling slot; on the other hand, the third frequency band is mainly influenced by the large coupling slot, which is consistent with what we talked about earlier in this section. So the antenna can be excited better by two coupling slots than by one. 


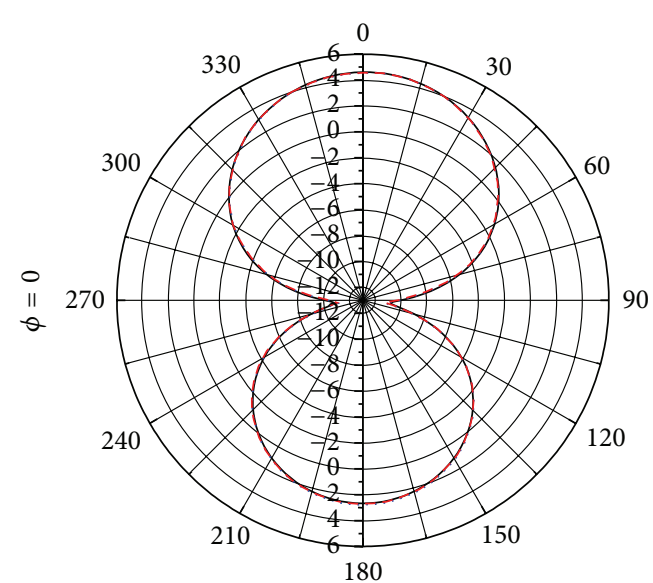

(a)

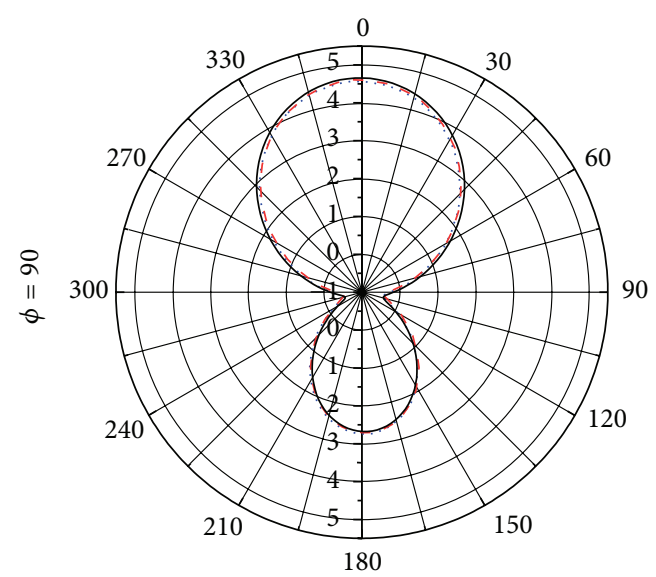

… $956 \mathrm{MHz}$

$968 \mathrm{MHz}$

(b)

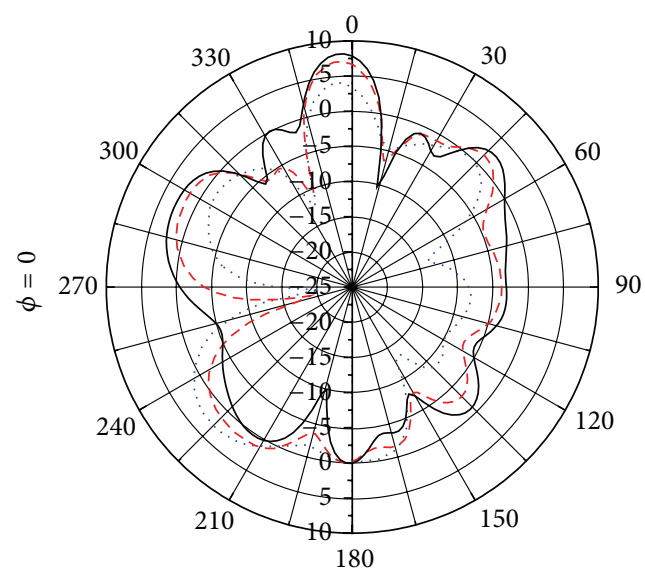

$\begin{array}{ll}\cdots & 8.81 \mathrm{GHz} \\ --- & 9.064 \mathrm{GHz}\end{array}$

$-9.28 \mathrm{GHz}$

(e)

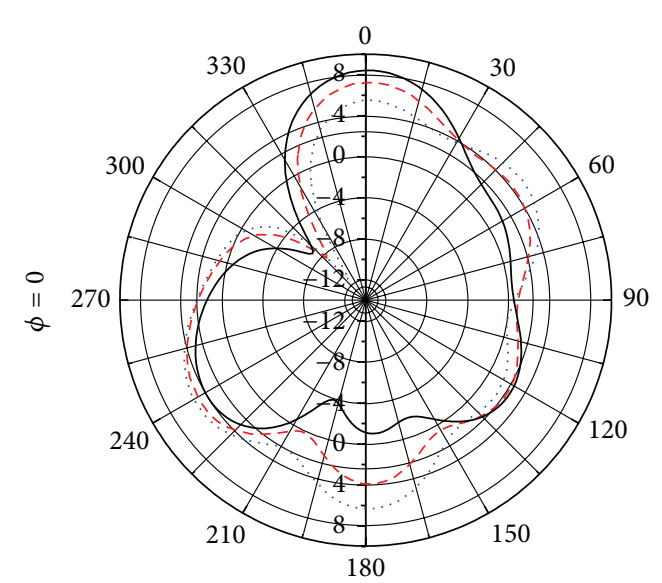

(c)

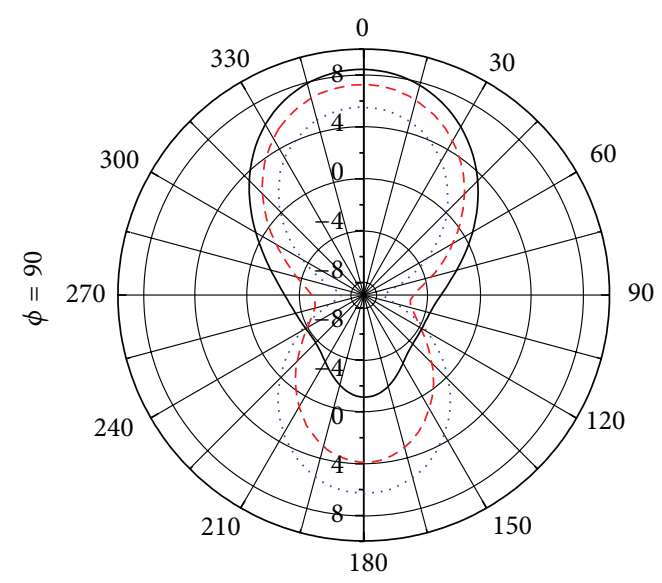

$\begin{array}{lll}\ldots . & 3.654 \mathrm{GHz} \quad-3.786 \mathrm{GHz}\end{array}$

(d)

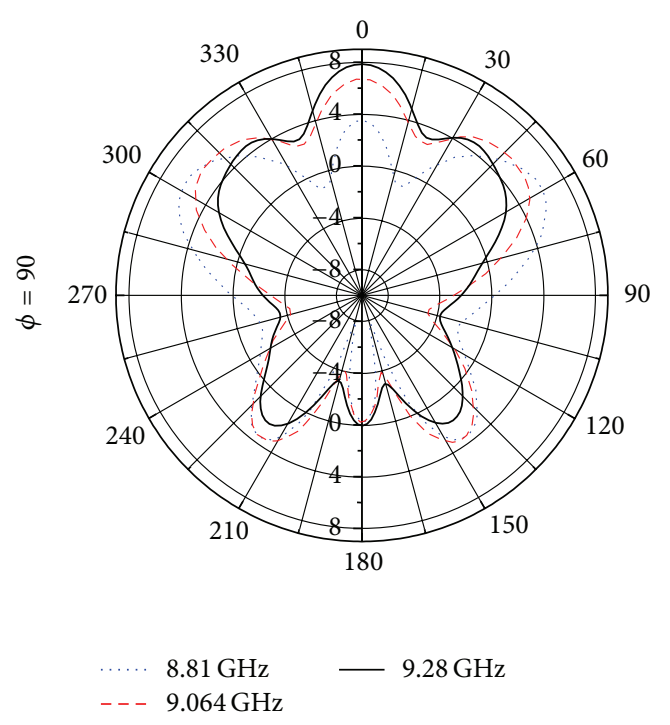

(f)

FIGURE 8: The radiation patterns of the two-layer Sierpinski patch antenna. (a) The radiation pattern of the first band (phi $=0$ ). (b) The radiation pattern of the first band ( $\mathrm{phi}=90)$. (c) The radiation pattern of the second band $(\mathrm{phi}=0)$. $(\mathrm{d})$ The radiation pattern of the second band (phi =90). (e) The radiation pattern of the third band ( $\mathrm{phi}=0)$. (f) The radiation pattern of the third band $(\mathrm{phi}=90)$. 


\section{Two-Layer Sierpinski Patch Antenna}

By introducing two coupling slots to the Sierpinski patch antenna, we get an improved performance on the radiation properties. However, the radiation properties at the third band still can be improved one step further. In this section, a two-layer Sierpinski patch antenna is introduced on the basis of the antenna discussed in Section 3. A parasitic layer located upon the radiating patch is introduced to enhance the directivity of the antenna, as shown in Figure 6. The other parts of this proposed antenna remain the same as the antenna discussed in Section 3. The size of the parasitic patch is $16 \mathrm{~mm} * 16 \mathrm{~mm}$, and the distance between the parasitic patch and the radiating patch is $3 \mathrm{~mm}$. The relative permittivity of the dielectric layer is 2.25. The simulated results of return loss and radiation pattern are shown in Figures 7 and 8. After introducing the parasitic patch, the proposed antenna still can work on $956 \mathrm{MHz}$ to $968 \mathrm{MHz}$, $3.654 \mathrm{GHz}$ to $3.78 \mathrm{GHz}$, and $8.81 \mathrm{GHz}$ to $9.28 \mathrm{GHz}$ three frequency bands. Moreover, it is clearly revealed in Figure 8 that the radiation pattern in each frequency band shows great consistency. The maximum gain in each band is $4.64 \mathrm{dBi}$, $8.46 \mathrm{dBi}$, and $7.85 \mathrm{dBi}$, respectively, which is higher than the antenna without parasitic patch.

\section{Conclusion}

A two-layer modified aperture coupled patch antenna with Sierpinski fractal geometry is presented in this paper. The proposed antenna can work on $956 \mathrm{MHz}$ to $968 \mathrm{MHz}$, $3.654 \mathrm{GHz}$ to $3.78 \mathrm{GHz}$, and $8.81 \mathrm{GHz}$ to $9.28 \mathrm{GHz}$ three frequency bands. By introducing two coupling slots, the antenna can perform better on the impedance matching and radiation properties than the original fractal antenna. What is more, a parasitic patch is also introduced in this paper to enhance the directivity of the proposed antenna. The maximum gain in each band is $4.64 \mathrm{dBi}, 8.46 \mathrm{dBi}$, and $7.85 \mathrm{dBi}$, respectively, while the gain of antenna without parasitic patch is only $4.56 \mathrm{dBi}$ at $960 \mathrm{MHz}, 7.87 \mathrm{dBi}$ at $3.68 \mathrm{GHz}$, and $4.82 \mathrm{dBi}$ at $8.8 \mathrm{GHz}$. The results show that the modified aperture coupled feed together with the parasitic patch can overcome the shortage on radiation properties of the fractal patch antenna.

\section{Conflict of Interests}

The authors declare that there is no conflict of interests regarding the publication of this paper.

\section{References}

[1] J. Anguera, C. Puente, C. Borja, and R. Montero, "Bowtie microstrip patch antenna based on the Sierpinski fractal," in Proceedings of the IEEE Antennas and Propagation Society International Symposium, vol. 3, pp. 162-165, July 2001.

[2] J. Anguera, C. Puente, C. Borja, and J. Romeu, "Miniature wideband stacked microstrip patch antenna based on the Sierpinski fractal geometry," in Proceedings of the IEEE Antennas and Propagation Society International Symposium, vol. 3, pp. 17001703, 2000.
[3] S. A. Kumar and T. K. Sreeja, "A modified fractal antenna for multiband applications," in Proceedings of the IEEE International Conference on Communication Control and Computing Technologies (ICCCCT '10), pp. 47-51, October 2010.

[4] C. Borja, G. Font, S. Blanch, and J. Romeu, "High directivity fractal boundary microstrip patch antenna," Electronics Letters, vol. 36, no. 9, pp. 778-779, 2000.

[5] D. H. Werner and S. Ganguly, "An overview of fractal antenna engineering research," IEEE Antennas and Propagation Magazine, vol. 45, no. 1, pp. 38-57, 2003.

[6] C. T. P. Song, P. S. Hall, H. Ghafouri-Shiraz, and I. Henning, "Fractal antenna research at University of Birmingham," in Proceedings of the 11th International Conference on Antennas and Propagation, vol. 2, pp. 724-727, Manchester, UK, July 2001.

[7] S. Raje, S. Kazemi, and H. R. Hassani, "Wideband stacked koch fractal antenna with $\mathrm{H}$-Shape aperture coupled feed," in Proceedings of the Asia-Pacific Microwave Conference (APMC '07), pp. 1-4, December 2007.

[8] S. N. Sinha and M. Jain, "A self-affine fractal multiband antenna," IEEE Antennas and Wireless Propagation Letters, vol. 6, pp. 110-112, 2007.

[9] T. Luintel and P. F. Wahid, "Modified Sierpinski fractal antenna," in Proceedings of the IEEE/ACES International Conference on Wireless Communications and Applied Computational Electromagnetics, pp. 578-581, April 2005.

[10] J. Yeo, R. Mittra, Y. Lee, and S. Ganguly, "A novel modified Sierpinski patch using shorting pins and switches for multiband applications," in Proceedings of the IEEE Antennas and Propagation Society International Symposium, vol. 4, pp. 90-93, June 2002.

[11] A. Constantine, Balanis, Antenna Theory Analysis and Design, John Wiley \& Sons, New Jersey, NJ, USA, 3rd edition, 2005.

[12] S. Shrestha, J.-J. Park, S.-K. Noh, and D.-Y. Choi, "Design of $2.45 \mathrm{GHz}$ Sierpinski fractal based miniaturized microstrip patch antenna," in Proceedings of the 18th Asia-Pacific Conference on Communications (APCC '12), pp. 36-41, October 2012. 

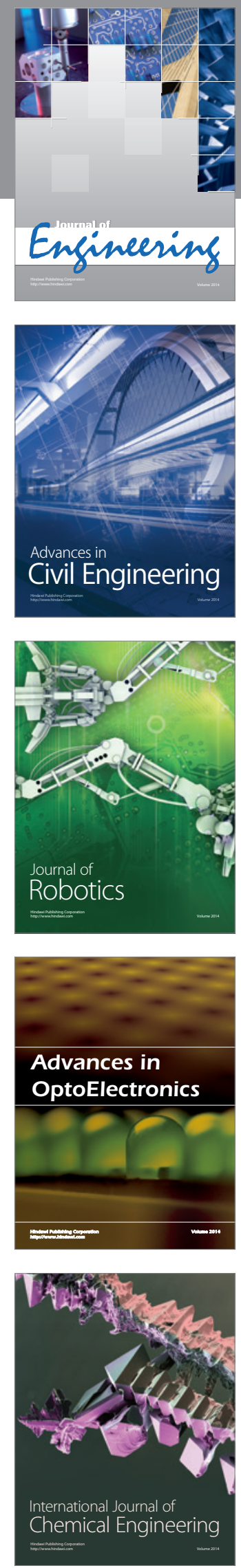

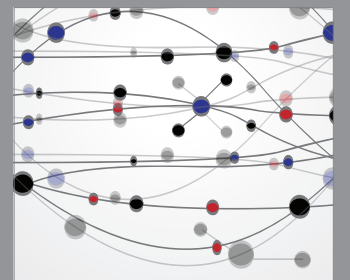

The Scientific World Journal
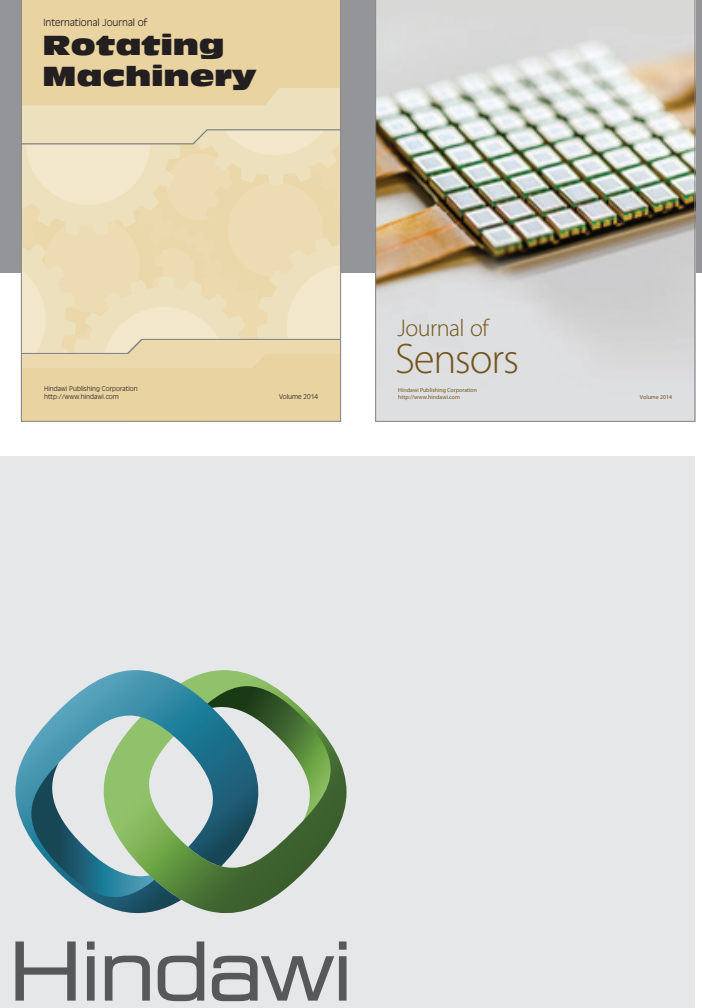

Submit your manuscripts at http://www.hindawi.com
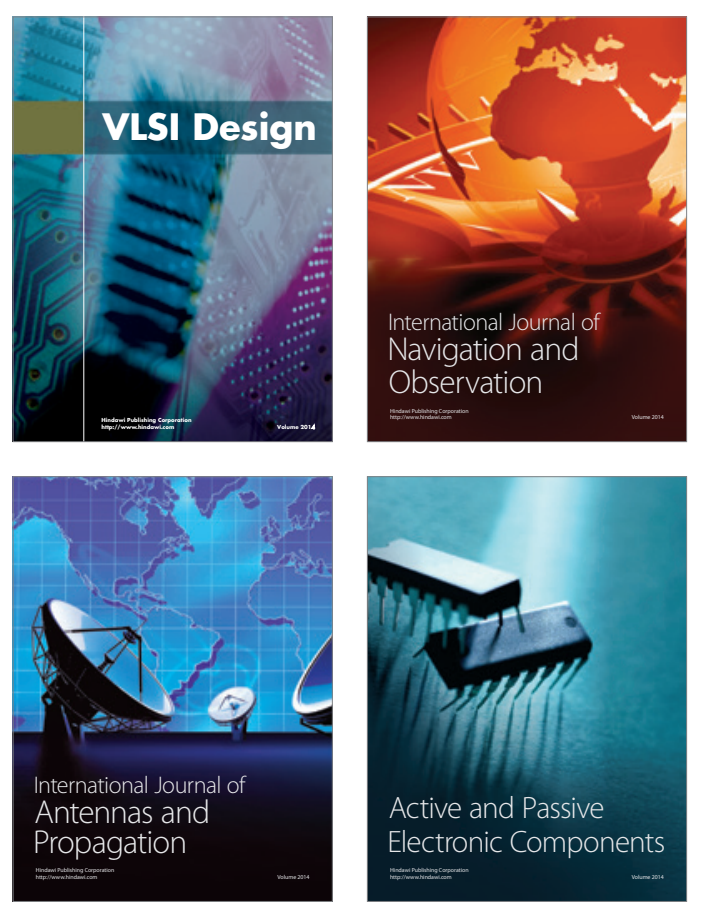
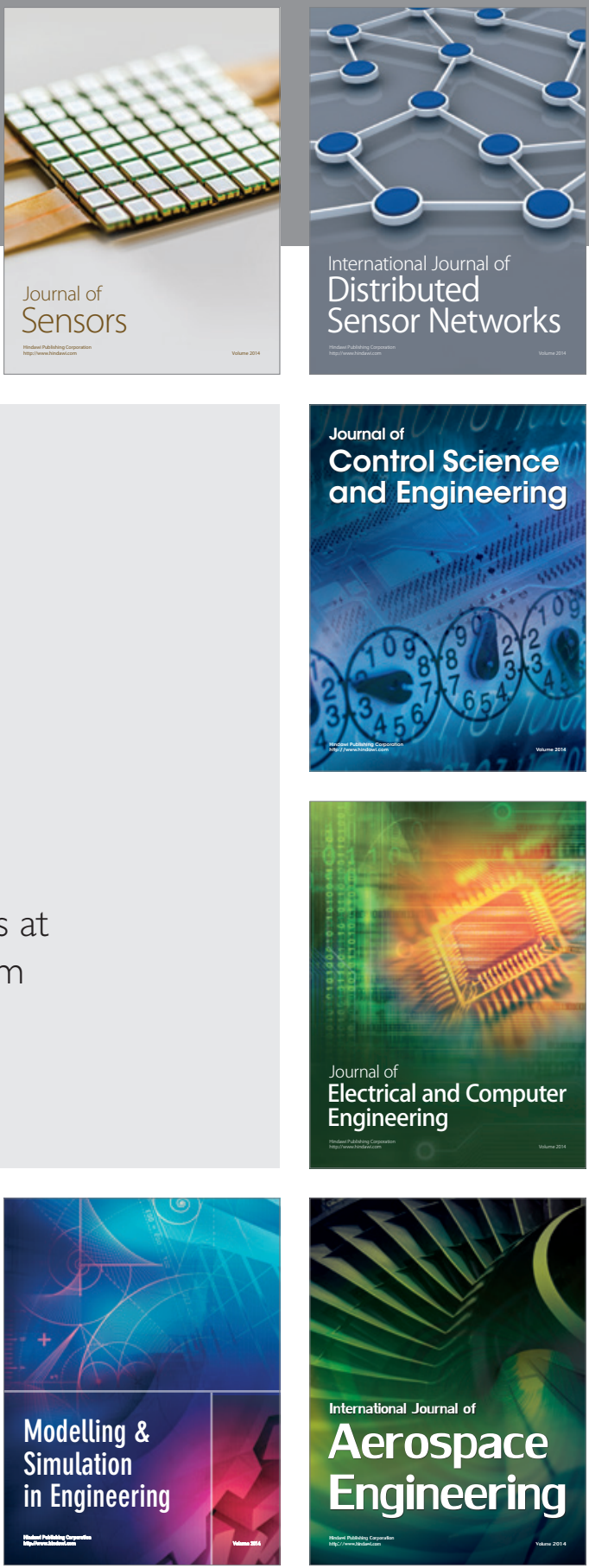

Journal of

Control Science

and Engineering
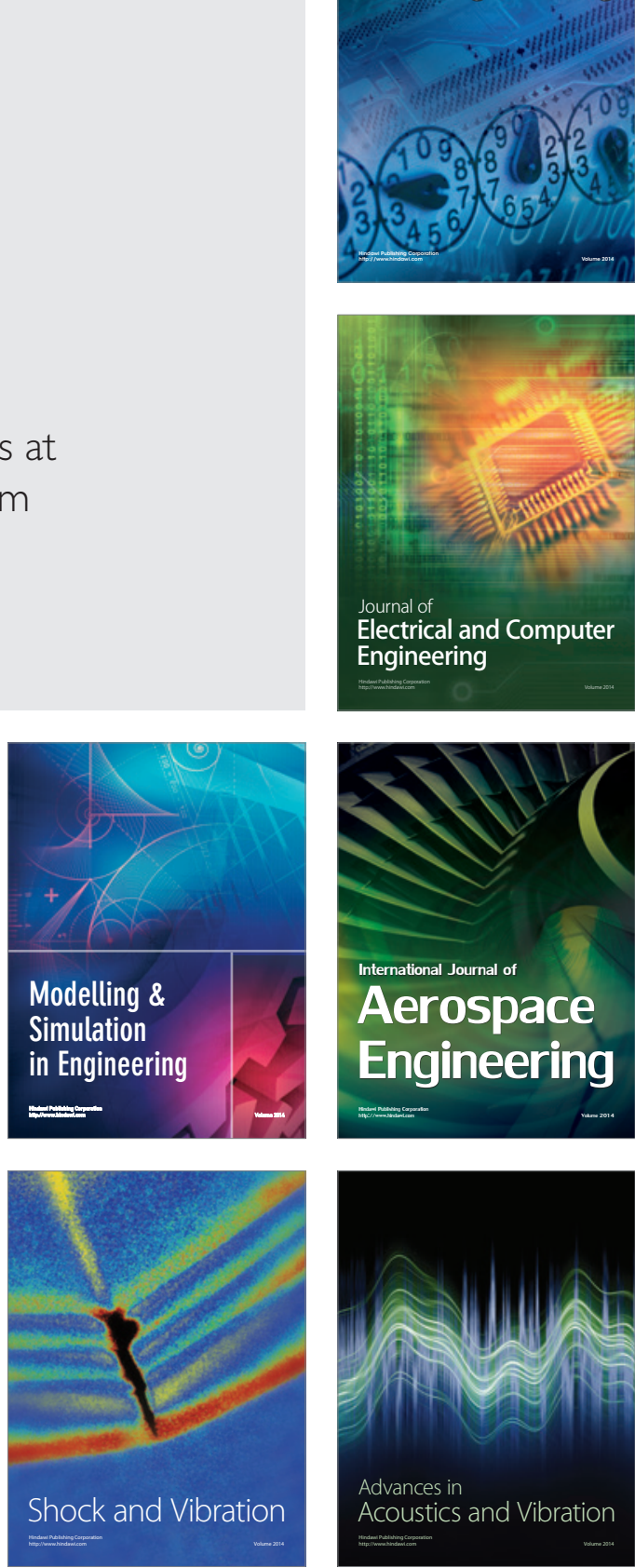